\title{
Autophagic flux promotes cisplatin resistance in human ovarian carcinoma cells through ATP-mediated lysosomal function
}

\author{
LIWEI MA ${ }^{1}$, YE XU² ${ }^{2}$, JING SU ${ }^{1}$, HUIMEI YU ${ }^{1}$, JINSONG KANG ${ }^{1}$, HONGYAN LI $^{1}$, \\ XIAONING LI ${ }^{1}$, QI XIE ${ }^{1}$, CHUNYAN YU ${ }^{3}$, LIANKUN SUN ${ }^{1}$ and YANG LI ${ }^{1}$ \\ ${ }^{1}$ Department of Pathophysiology, College of Basic Medical Sciences, Jilin University, Changchun, Jilin 130021; \\ ${ }^{2}$ Medical Research Lab, Jilin Medical University; ${ }^{3}$ Department of Pathology, Basic Medical College, \\ BeiHua University, Changchun, Jilin 132013, P.R. China
}

Received July 6, 2015; Accepted August 18, 2015

DOI: $10.3892 /$ ijo.2015.3176

\begin{abstract}
Lysosomes are involved in promoting resistance of cancer cells to chemotherapeutic agents. However, the mechanisms underlying lysosomal influence of cisplatin resistance in ovarian cancer remain incompletely understood. We report that, compared with cisplatin-sensitive SKOV3 cells, autophagy increases in cisplatin-resistant SKOV3/DDP cells treated with cisplatin. Inhibition of early-stage autophagy enhanced cisplatin-mediated cytotoxicity in SKOV3/DDP cells, but autophagy inhibition at a later stage by disturbing autophagosome-lysosome fusion is more effective. Notably, SKOV3/DDP cells contained more lysosomes than cisplatin-sensitive SKOV3 cells. Abundant lysosomes and lysosomal cathepsin D activity were required for continued autolysosomal degradation and maintenance of autophagic flux in SKOV3/DDP cells. Furthermore, SKOV3/DDP cells contain abundant lysosomal ATP required for lysosomal function, and inhibition of lysosomal ATP accumulation impaired lysosomal function and blocked autophagic flux. Therefore, our findings suggest that lysosomes at least partially contribute to cisplatin resistance in ovarian cancer cells through their role in cisplatin-induced autophagic processes, and provide insight into the mechanism of cisplatin resistance in tumors.
\end{abstract}

\section{Introduction}

Ovarian cancer is often diagnosed at an advanced stage (III or IV) and is typically treated with a combination of cytoreductive surgery and platinum-based chemotherapy (1-3).

Correspondence to: Professor Liankun Sun or Professor Yang Li, Department of Pathophysiology, College of Basic Medical Sciences, Jilin University, 126 Xinmin Street, Changchun, Jilin 130021, P.R. China

E-mail: sunlk@jlu.edu.cn

E-mail: lyang@jlu.edu.cn

Key words: autophagic flux, ATP, lysosomal function, cisplatin resistance, ovarian carcinoma cells
Platinum-based cisplatin is a first-line therapeutic agent used in the treatment of multiple cancers, including ovarian cancer. Cisplatin acts by inducing DNA damage, triggering cell cycle arrest, and initiating apoptosis (4). However, many ovarian cancer patients develop acquired cisplatin resistance, resulting in failure of chemotherapy (5). Several recent studies demonstrate that adaptive responses, such as endoplasmic reticulum (ER) stress and autophagy, can promote cisplatin resistance in cancer cells $(6,7)$.

Autophagy is characterized by sequestration of cytoplasmic components within autophagosomes. These autophagosomes subsequently fuse with lysosomes to form autolysosomes in which cytoplasmic materials including organelles are degraded (8-10). Many chemotherapeutic agents, including cisplatin, can induce autophagy $(8,9)$. This induction of autophagy can have either pro-survival or pro-death effects to the anticancer drugs (11). Autophagy is induced under many physiological and pathological conditions, and it often promotes survival of cancer cells (5). For example, treatment of HeLa cells with ammonium chloride or chloroquine (CQ) to inhibit autophagy disrupts autolysosome function and enhances cellular sensitivity to cisplatin $(12,13)$. Consistently, our previous results demonstrate that p62/SQSTM1 maintains autophagic flux and alleviates ER stress by clearing accumulation of ubiquitinated proteins, thereby promoting cisplatin resistance in human ovarian cancer cells $(13,14)$. Autophagy is a lysosomal-dependent process in which lysosomes are consumed over time. Therefore, normal lysosomal numbers and function are required for maintaining autophagic flux (15). Examining lysosomal maintenance may further our understanding of the mechanisms underlying autophagy-mediated cisplatin resistance.

Lysosomes can degrade major cellular macromolecules and damaged organelles $(16,17)$. Within the lysosome, members of the lysosome-associated membrane protein (LAMP) family contribute to a glycocalyx that protects the structural integrity of lysosomal membranes from lysosomal hydrolases (18-20). Both LAMP1 and LAMP2 are required for successful autolysosome fusion, as LAMP1 or LAMP2 defects lead to accumulation of autophagic vacuoles and inhibits autophagy (21). Furthermore, the acidic environment within the lysosome ( $\mathrm{pH} 4-5)$ is a necessary condition for lysosomal 
protease activation (22). Lysosomal acidic environment and protease are both required for normal lysosomal function. This acidic environment enables indirect evaluation of lysosomal function using stains such as LysoTracker. Moreover, when lysosomal function is activated in the course of autophagy, LysoTracker staining is increased (23). Investigation of the mechanisms involved in regulating lysosomal function may also aid in understanding autophagy-mediated cisplatin resistance.

Lysosomes are dynamic organelles within living cells, and have both pro-survival and pro-death roles during chemotherapeutic treatment of cancer cells. Lysosomal sequestration of chemotherapeutic agents not only prevents drugs from reaching their intracellular targets, but also induces lysosomal biogenesis by triggering translocation of transcription factor EB from the cytoplasm to the nucleus (24). Therefore, the lysosome can determine whether a tumor cell exhibits chemotherapeutic resistance.

The $\mathrm{pH}$ gradient between the lysosomal lumen and the cytoplasm has been recently found to determine the extent of lysosomal sequestration of chemotherapeutic agents (25). $\mathrm{V}$-ATPase is a protein complex which regulates lysosomal luminal acidity (26). ATP-sensitive sodium and potassium channels maintain the low pH of the lysosomal lumen, consuming ATP in the process (27). However, lysosomes contain abundant ATP, which is sufficient for maintaining normal lysosomal physiology (28) and enabling protease activation (29). Accumulation of lysosomal ATP can be impaired, leading to lysosomal cathepsin D activity inhibition, formation of lipofuscin aggregates, and even cell death (28). Lysosomal hydrolases can also move into the cytoplasm and retain transient activity, enabling them to trigger mitochondria-lysosome crosstalk to promote cell death $(30,31)$. Precisely how the abundance of lysosomal ATP regulates lysosome function and homeostasis remains unclear, and requires further investigation.

We investigated cisplatin-resistance in SKOV3/DDP cells and examined lysosomal involvement in cisplatin-induced autophagy. Cisplatin induced a more obvious autophagic response in cisplatin-resistant SKOV3/DDP cells than in cisplatin-resistance SKOV3/DDP cells. Moreover, inhibiting autophagy by disturbing autophagosome-lysosome fusion sensitized cisplatin-resistant SKOV3/DDP cells to cisplatin. SKOV3/DDP cells possess abundant lysosomes and cathepsin D, which facilitated clearance of accumulated materials via autophagy. Furthermore, SKOV3/DDP lysosomes contain abundant ATP. We inhibited lysosomal ATP accumulation and observed impaired lysosomal function. These findings suggest an important role for lysosomal ATP levels in promoting resistance to chemotherapeutic agents.

\section{Materials and methods}

Cell culture. Cisplatin-sensitive ovarian carcinoma SKOV3 cells and their cisplatin-resistant clone SKOV3/DDP were obtained from the Chinese Academy of Medical Sciences and Peking Union Medical College. Both cell lines were maintained at $37^{\circ} \mathrm{C}$ in a $5 \% \mathrm{CO}_{2}$ and $95 \%$ air atmosphere in Roswell Park Memorial Institute (RPMI)-1640 culture medium (Gibco Life Technologies, Carlsbad, CA, USA) supplemented with $10 \%$ fetal bovine serum (Invitrogen, Carlsbad, CA, USA), $100 \mathrm{U} / \mathrm{ml}$ penicillin, and $100 \mathrm{U} / \mathrm{ml}$ streptomycin. Cisplatin-resistant SKOV3/DDP cells were cultured in the presence of $1 \mu \mathrm{g} / \mathrm{ml}$ cisplatin to maintain resistance.

Cell viability assay. The MTT assay was used to determine cell viability. Cells were seeded in 96-well plates at a density of $1 \times 10^{4}$ cells/well. Each condition was mirrored in six wells. The following day, cells were treated with different concentrations of cisplatin and incubated for $24 \mathrm{~h}$. Next, $20 \mu \mathrm{l}$ MTT reagent [5 mg/ml in phosphate-buffered saline (PBS); Sigma-Aldrich, St. Louis, MO, USA] was added to each well and incubated for $4 \mathrm{~h}$. Lastly, $150 \mu \mathrm{l}$ dimethylsulfoxide was added to each well and absorbance at $570 \mathrm{~nm}$ measured using a Vmax Microplate Reader (Molecular Devices, LLC, Sunnyvale, CA, USA).

Immunofluorescence staining and confocal laser microscopy. Cells were seeded onto coverslips in 24-well plates at $\left(5 \times 10^{4}\right.$ cells/well) and incubated overnight. Apoptotic nuclear changes were detected using Hoechst 33258 (Sigma-Aldrich) staining. Following cisplatin treatment, cells were washed with cold PBS three times, fixed in $4 \%$ (w/v) paraformaldehyde/PBS for $20 \mathrm{~min}$, and then washed with cold PBS three times. After fixation, cells were subjected to proteinase $\mathrm{K}$ digestion for $1 \mathrm{~min}$, washed twice with PBS, permeabilized with $0.1 \%$ Triton $\mathrm{X}-100$ for $5 \mathrm{~min}$, washed with cold PBS three times, and then blocked with bovine serum albumen for $30 \mathrm{~min}$. Cells were incubated with primary antibody (LC3 or LAMP1 - all at 1:100 dilution) overnight at $4^{\circ} \mathrm{C}$, washed three times with PBS, and stained with FITC/Texas Red-conjugated secondary antibodies (1:400 dilution; all antibodies, Santa Cruz Biotechnology, Inc., Santa Cruz, CA, USA) for $30 \mathrm{~min}$ in the dark. Cells were treated with Hoechst $33342 / \mathrm{H}_{2} \mathrm{O}(1 \mu \mathrm{g} / \mathrm{ml})$ for $2 \mathrm{~min}$, and then washed three times with PBS. Images were acquired by an Olympus FV1000 confocal laser microscope.

ATP staining. Cells were cultured onto coverslips as described above and treated with combinations of 4,4'-diisothiocyano-2,2'-stilbenedisulfonic acid (DIDS; Sigma-Aldrich) and cisplatin. Cells were then incubated with $10 \mu \mathrm{M}$ quinacrine (Merck Millipore, Darmstadt, Germany) together with $50 \mathrm{nM}$ LysoTracker Red DND-99 (Invitrogen) for $30 \mathrm{~min}$ at $37^{\circ} \mathrm{C}$. Quinacrine binds ATP, and its fluorescence signal intensity indicates ATP levels (32). Following staining, cells were washed three times with PBS and images were acquired using an Olympus FV1000 confocal laser microscope.

Measurement of cathepsin D activity. Cathepsin D activity in cell lysates was detected using a fluorometric cathepsin D activity assay kit (Biovision, San Francisco, CA, USA) according to the manufacturer's instructions. Fluorescence intensity at an excitation/emission of 328/460 $\mathrm{nm}$ was measured using a Packard Bioscience Fusion ${ }^{\mathrm{TM}}$ instrument. Three independent measurements were made for each sample.

Western blot analysis. Cells subjected to desired treatments were harvested, washed twice with cold PBS, and then gently scraped into $120 \mu \mathrm{l}$ of RIPA buffer. Cell lysates were sonicated for $30 \mathrm{sec}$ on ice and then lysed at $4^{\circ} \mathrm{C}$ for $45 \mathrm{~min}$. Cell lysates were centrifuged at $3,000 \mathrm{x} \mathrm{g}$ for $15 \mathrm{~min}$, and supernatant 
protein concentrations were determined using the Bio-Rad kit (Pierce Biotechnology, Inc., Rockford, IL, USA). For western blot analysis, equivalent amounts of lysate proteins (30-50 $\mu \mathrm{g}$ ) were separated by $12 \% \mathrm{w} / \mathrm{v}$ SDS-polyacrylamide gel electrophoresis and transferred onto nitrocellulose transfer membranes (Millipore Corp., Bedford, MA, USA). Membranes were blocked with $5 \%$ (w/v) skim milk in buffer [PBST: $10 \mathrm{mM}$ Tris-HCl (pH 7.6), $100 \mathrm{mM} \mathrm{NaCl}$, and 0.1\% (v/v) Tween-20] for $1 \mathrm{~h}$ at room temperature, and incubated with primary antibodies (Santa Cruz Biotechnology, Inc.) overnight at $4^{\circ} \mathrm{C}$. The following day, membranes were washed with PBST and incubated with horseradish peroxidase-conjugated secondary antibodies (Thermo Fisher Scientific, Waltham, MA, USA) at 1:2,000 dilution for $1 \mathrm{~h}$ at room temperature. After washing the membranes with PBST, immunodetection was performed using ECL reagent (Thermo Fisher Scientific) and visualized using a Syngene Bio Imaging (Synoptics, Cambridge, UK). Protein levels were quantified by densitometry using Quantity One software (Bio-Rad Laboratories, Inc., Hercules, CA, USA).

Flow cytometry. Cells were trypsinized following desired treatments and incubated with Muse ${ }^{\mathrm{TM}}$ Annexin V and Dead Cell reagent for $20 \mathrm{~min}$ at room temperature. Apoptotic cells were then analyzed with a Muse ${ }^{\mathrm{TM}}$ Cell Analyzer. All experiments reported in this study were repeated three times.

Statistics. Results are representative of three independent experiments performed in triplicate and presented as means \pm SD. One-way ANOVA was used to perform statistical analysis of the data. $\mathrm{P}<0.05$ was regarded as statistically significant.

\section{Results}

Autophagic activity and lysosome numbers are higher in cisplatin-resistant SKOV3/DDP cells than in cisplatin-sensitive SKOV3 cells. SKOV3/DDP cells underwent less apoptosis and exhibit increased cisplatin resistance compared with SKOV3 cells following treatment with cisplatin for $24 \mathrm{~h}$ (Fig. A-C).

Next, we examined the protein expression levels of p62, LC3I, and LC3II in both cisplatin-sensitive SKOV3 cells and cisplatin-resistant SKOV3/DDP cells. The LC3II/LC3I ratio was significantly increased in SKOV3/DDP cells, especially at $12 \mathrm{~h}$, while p62 protein levels in SKOV3/DDP cells decreased gradually (Fig. 1D and E).

Autophagy requires lysosomal degradation of cytoplasmic materials. Therefore, we next investigated the change of lysosomes in SKOV3 and SKOV3/DDP cells following exposure to cisplatin. Compared with cisplatin-sensitive SKOV3 cells, cisplatin-resistant SKOV3/DDP cells expressed more LAMP1 (Fig. 1F and G). Lysosomal proteases are required for macromolecule degradation in lysosomes, and cathepsin D is an important aspartic protease in the lysosome. Compared with SKOV3 cells treated with cisplatin, SKOV3/DDP cells expressed both a higher level of total cathepsin D, and a higher level of activated cathespin D (Fig. 1H and I). Taken together, these results indicate that abundant lysosomes exist in cisplatin-resistant SKOV3/DDP cells treated with cisplatin, and autophagy was induced in these cells. Furthermore, lysosomes may sustain cellular metabolism and maintain cell homeostasis through autophagy.

Lysosomal function increases with cisplatin-induced autophagy in cisplatin-resistant SKOV3/DDP cells. We next investigated changes to lysosomal activity alongside cisplatin-induced autophagy. First, compared with SKOV3 cells, LysoTracker staining was increased in SKOV3/DDP cells treated with cisplatin, especially at $4 \mathrm{~h}$ (Fig. 2A). This suggests increased acidification of lysosomes. Second, compared with cisplatin-sensitive SKOV3 cells, cathepsin D activity was significantly higher under normal conditions in cisplatin-resistant SKOV3/DDP cells. Notably, cathepsin D activity was reduced significantly at $12 \mathrm{~h}$ in SKOV3 cells treated with cisplatin, but unchanged in SKOV3/DDP cells following the same treatment (Fig. 2B). Lysosomes can be differentiated from autolysosomes on the basis of LC3 staining: lysosomes are $\mathrm{LAMP}^{+}$and $\mathrm{LC}^{-}$, while autolysosomes are $\mathrm{LAMP}^{+}$ and $\mathrm{LC}^{+}$(33). SKOV3/DDP cells treated with cisplatin had increased LC3 staining, and therefore more autolysosomes, at $4 \mathrm{~h}$, but decreased staining at 6, 12 and $24 \mathrm{~h}$ (Fig. 2C and D). Furthermore, the size and number of lysosomes in SKOV3/DDP cells slightly decreased at $6 \mathrm{~h}$, but was restored to an almost normal level at $12 \mathrm{~h}$ following treatment with cisplatin (Fig. 2D). These results indicate that lysosomal function is increased during cisplatin-induced autophagy in SKOV3/DDP cells, and abundant lysosomes contribute to autolysosome formation.

Inhibiting autophagy enhances cisplatin-mediated cytotoxicity in cisplatin-resistant SKOV3/DDP cells, but targeting the lysosome to disturb autolysosome formation is more effective. We next examined whether inhibition of a specific stage of autophagy could protect SKOV3/DDP cells from cisplatin-induced autophagy. Cisplatin-resistant SKOV3/ DDP cells were treated with 3-methyladenine (3-MA), which inhibits autophagy at an early stage by interfering with recruitment of the class III PI3K Vps34, or antimalarial CQ, a late-stage autophagy inhibitor that impairs lysosome acidification, to disrupt autolysosome formation.

No significant toxic effect was observed following treatment of SKOV3/DDP cells with $10 \mathrm{mM} 3-\mathrm{MA}$ or $50 \mu \mathrm{M} \mathrm{CQ}$. MTT assays revealed that neither 3-MA or CQ alone had a significant impact on cell viability. However, combining either inhibitor with cisplatin significantly decreased the growth of SKOV3/DDP cells, with the CQ-cisplatin combination being slightly more effective (Fig. 3A). Autolysosomes were rarely observed in SKOV3/DDP cells treated with a combination of 3-MA and cisplatin (Fig. 3B). However, SKOV3/DDP cells possessed enlarged autolysosomes following co-treatment with CQ and cisplatin (Fig. 3B). Moreover, the number of autolysosomes was increased following CQ-cisplatin treatment. Inhibition of autophagy and/or cisplatin could abolish lysosomal activity in SKOV3/DDP cells (Fig. 3C). Moreover, cathepsin D activity was significantly lowered following treatment with CQ and/or cisplatin (Fig. 3D).

Compared with cells treated with cisplatin alone, combination treatment of 3-MA and cisplatin in SKOV3/DDP cells decreased the ratio of LC3II/LC3I and inhibited p62 degradation (Fig. 3E and F). Additionally, cisplatin-induced 


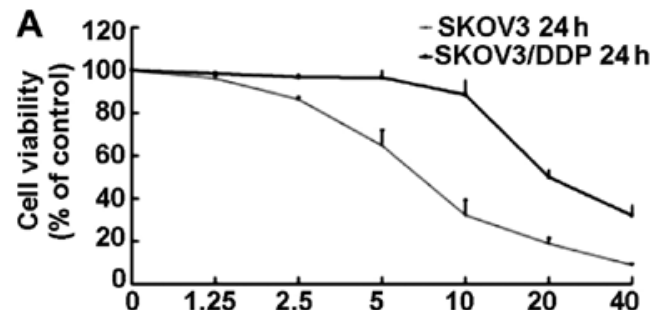

B

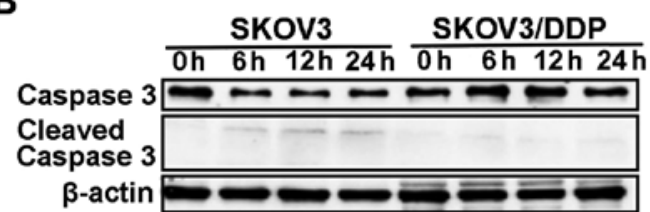

C

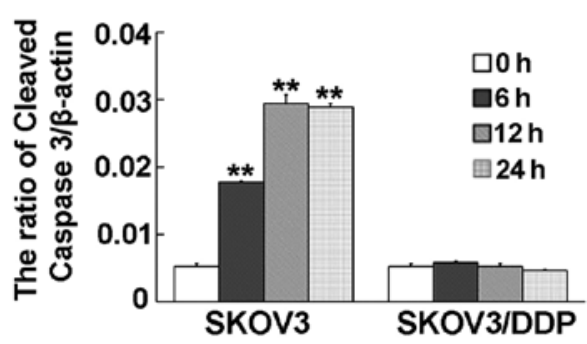

D

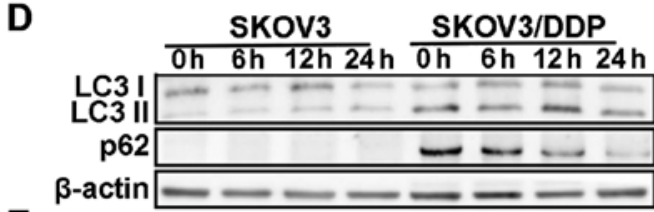

$E$

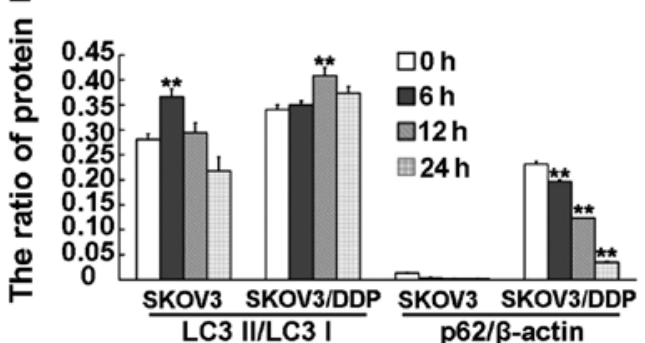

F

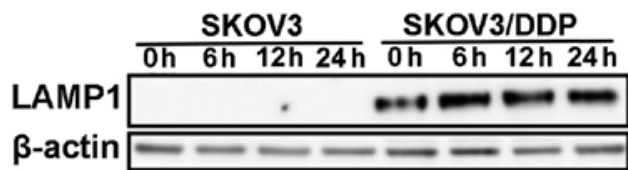

G

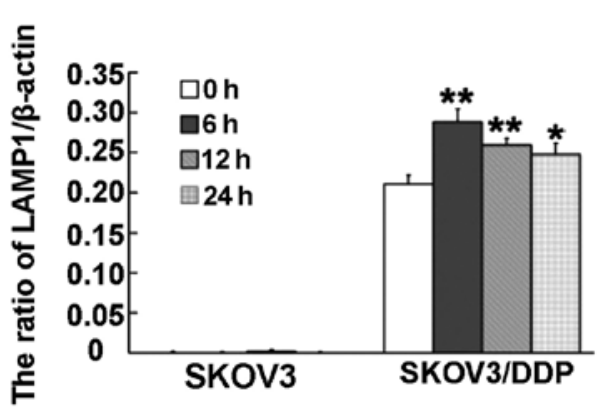

H

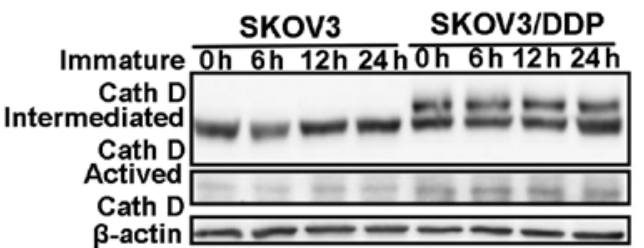

I

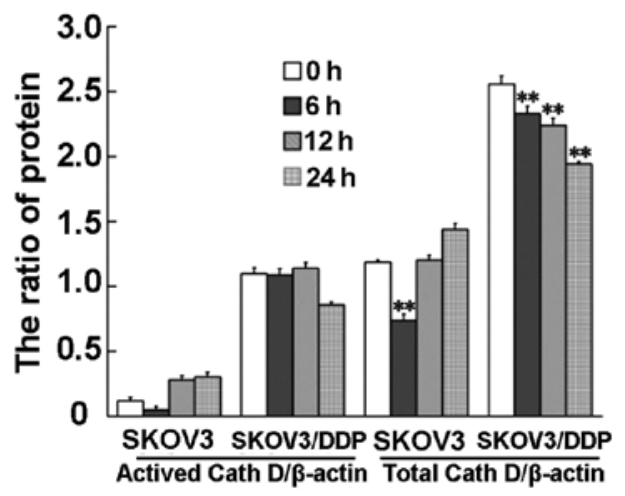

Figure 1. Cisplatin-sensitive SKOV3 and cisplatin-resistant SKOV3/DDP cells exhibit differences in autophagy and lysosome function. (A) SKOV3 and SKOV3/DDP cells were treated with indicated concentrations of cisplatin for $24 \mathrm{~h}$. Cell viability was evaluated by MTT assay. Data are presented as mean \pm SD, $\mathrm{n}=3$. (B and D) Western blot analysis of levels of caspase-3, cleaved caspase-3, LC3II, LC3I, and p62 protein in SKOV3 and SKOV3/DDP cells treated with $6 \mu \mathrm{g} / \mathrm{ml}$ cisplatin. (C and E) Quantitation of cleaved caspase-3, LC3II/LC3I, and p62 protein levels. Data are presented as mean $\pm \mathrm{SD}, \mathrm{n}=3$, ${ }^{* *} \mathrm{P}<0.01$. (F) Western blot analysis of LAMP1 levels in SKOV3 and SKOV3/DDP cells treated with $6 \mu \mathrm{g} / \mathrm{ml}$ cisplatin. (G) Quantitation of LAMP1 protein. Data are presented as mean $\pm \mathrm{SD}, \mathrm{n}=3 .{ }^{* *} \mathrm{P}<0.01$. $(\mathrm{H})$ Western blot analysis of cathepsin D protein levels in SKOV3 and SKOV3/DDP cells treated with $6 \mu \mathrm{g} / \mathrm{ml}$ cisplatin. (I) Quantitation of active cathepsin D and total cathepsin D protein levels. Data are presented as mean $\pm \mathrm{SD}, \mathrm{n}=3$. ${ }^{*} \mathrm{P}<0.05^{* *} \mathrm{P}<0.01$ vs. control.

upregulation of LC3II was further augmented by CQ-mediated inhibition of autolysosome formation. Cisplatin in combination with CQ reduced degradation of p62 in SKOV3/DDP cells. More ubiquitinated proteins were present in SKOV3/ DDP cells treated with a combination of cisplatin and 3-MA or $\mathrm{CQ}$, with the greatest amount found following cisplatin and CQ treatment (Fig. 3G and H). These results suggest that inhibiting autophagy by targeting the lysosome enhances cisplatin-induced cytotoxicity and disturbs autolysosome function in SKOV3/DDP cells.

Inhibition of autophagy by targeting the lysosome results in cell death through activation of mitochondria-lysosome crosstalk in cisplatin-resistant SKOV3/DDP cells. We next investigated apoptosis induction in SKOV3/DDP cells treated with cisplatin in combination with inhibition of autophagy.

Apoptotic populations of cells treated with cisplatin and 3-MA or CQ were quantified using the Muse ${ }^{\mathrm{TM}}$ Annexin V and Dead Cell assay. Compared with cisplatin alone, co-treatment with cisplatin and 3-MA or CQ enhanced the rate of cell apoptosis, with the CQ-cisplatin combination being more effective (Fig. 4A). We then examined whether the mitochondrial apoptotic pathway was initiated by measuring expression levels of Bax, Bcl-2 and cleaved caspase-3. Combined treatment of SKOV3/DDP cells with cisplatin and 3-MA or CQ increased the ratio of $\mathrm{Bax} / \mathrm{Bcl}-2$ and promoted activation of 
A

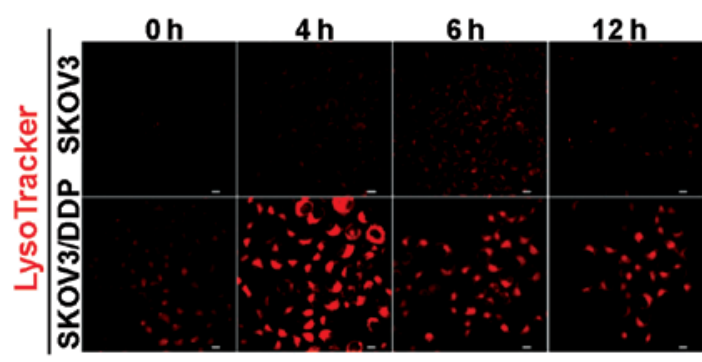

C

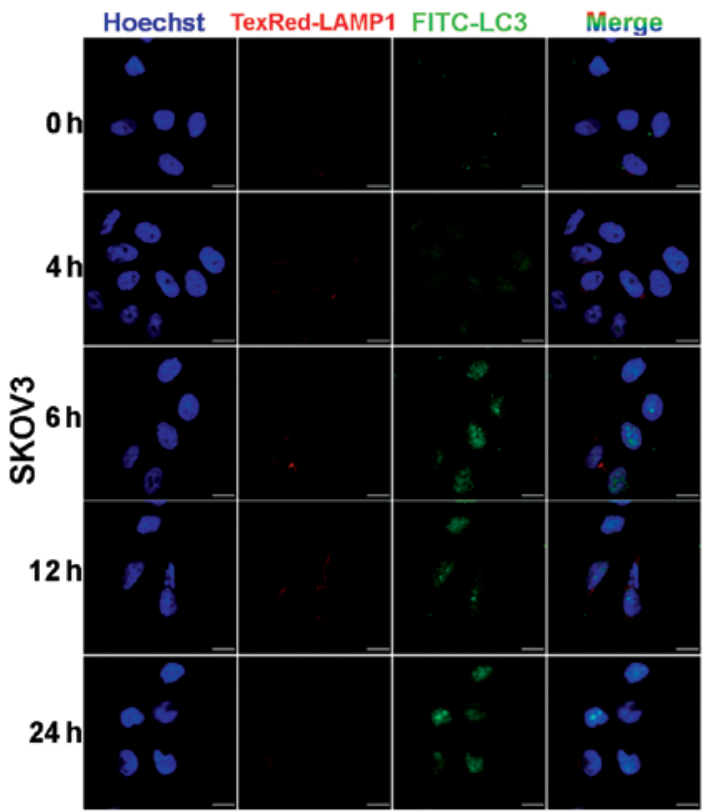

B
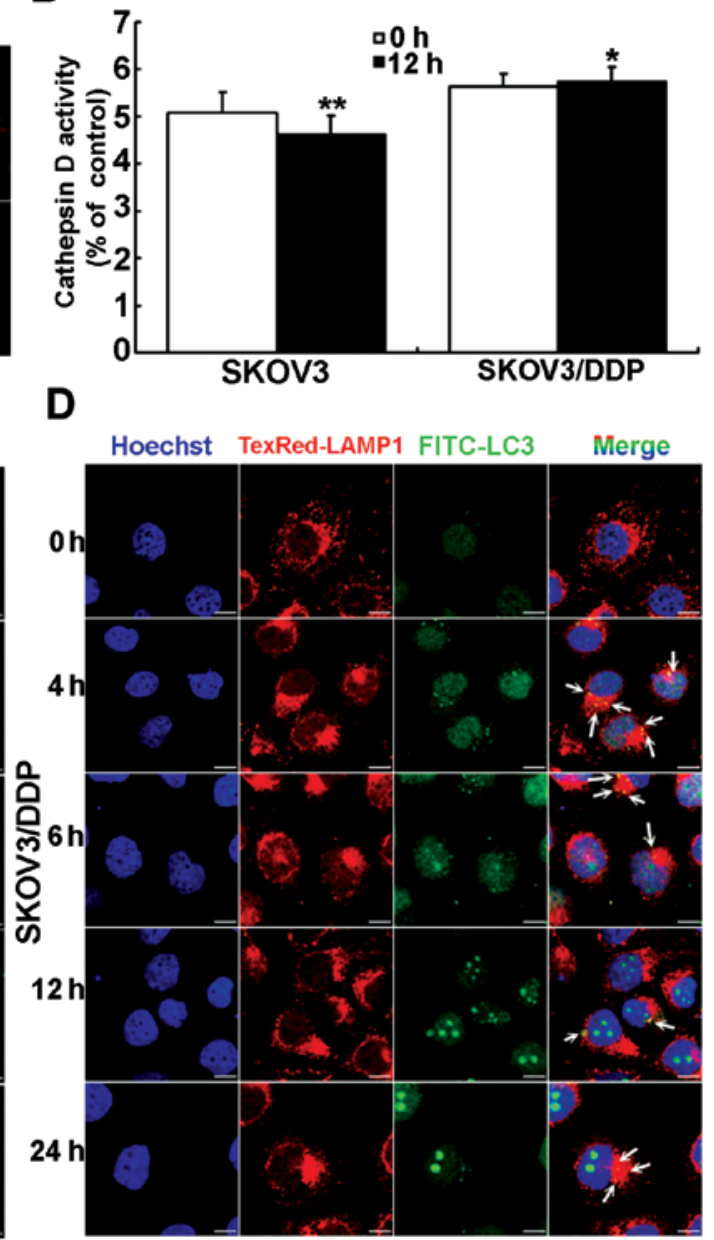

Figure 2. Activation of lysosomal function during cisplatin-induced autophagy in cisplatin-resistant SKOV3/DDP cells. (A) SKOV3 and SKOV3/DDP cells were treated with $6 \mu \mathrm{g} / \mathrm{ml}$ cisplatin for $0,4,6$ and $12 \mathrm{~h}$. Staining with LysoTracker Red DND-99 (LTR) was observed under confocal microscopy (scale bar, $10 \mu \mathrm{m}$ ). (B) Cells were lysed in CD cell lysis buffer following treatment with $6 \mu \mathrm{g} / \mathrm{ml}$ cisplatin for $12 \mathrm{~h}$. Cell lysates were analyzed using a cathepsin D activity assay. Data are presented as mean $\pm \mathrm{SD}, \mathrm{n}=3 .{ }^{* *} \mathrm{P}<0.01$ vs. control. (C and D) Colocalization of LAMP1 and LC3 in SKOV3 cells and SKOV3/DDP cells treated with $6 \mu \mathrm{g} / \mathrm{ml}$ cisplatin for $0,4,6,12$ and $24 \mathrm{~h}$ (scale bar, $10 \mu \mathrm{m}$; arrows indicate colocalization of LAMP1 and LC3).

caspase-3, with cisplatin-CQ being more effective (Fig. 4B and $\mathrm{C}$ ). Because the lysosome targeting effectively induced SKOV3/DDP cell apoptosis, we next investigated whether lysosomal cell death occurred. The ratio of $\mathrm{tBid} / \mathrm{Bid}$ in SKOV3/DDP cells following treatment with CQ and cisplatin was higher than that following treatment with 3-MA and cisplatin (Fig. 4D and E). Cells treated with combination CQ and cisplatin accumulated more cathepsin D than cells treated with either cisplatin alone or a combination of 3-MA and cisplatin (Fig. 4D and E). Therefore, while inhibition of autophagy overcame cisplatin resistance in SKOV3/DDP cells, targeting the lysosome could also enhance cisplatin-induced cell death by triggering mitochondria-lysosome crosstalk.

Inhibition of cathepsin D impairs autophagic degradation in cisplatin-resistant SKOV3/DDP cells. We next investigated whether cathepsin D contributes to protein degradation during autophagy in cisplatin-resistant SKOV3/DDP cells by inhibiting cathepsin D and measuring autophagic flux. Cells were treated with $80 \mu \mathrm{M}$ pepstatin $\mathrm{A}$, a potent cathepsin $\mathrm{D}$ inhibitor. Cathepsin D activity was significantly decreased in SKOV3/DDP cells treated with pepstatin A and/or cisplatin (Fig. 5A). Consistently, treatment with pepstatin A and/or cisplatin abolished LysoTracker staining in SKOV3/DDP cells (Fig. 5B). These findings suggest that inhibition of autolysosomal protein degradation by pepstatin A during cisplatin treatment could impair lysosomal function.

Inhibition of cathepsin D activity also led to an accumulation of enlarged autolysosomes, possibly because of accumulated undegraded materials within autolysosomes (Fig. 5C). Western blot analysis identified decreased p62 degradation and increased accumulation of LC3II (Fig. 5D and E). Additionally, inhibiting cathepsin $\mathrm{D}$ activity led to accumulation of ubiquitinated proteins (Fig. $5 \mathrm{~F}$ and $\mathrm{G}$ ). These data suggest that cathepsin D activity is required for autophagic degradation and lysosomal function during autophagy in cisplatin-resistant SKOV3/DDP cells.

Inhibition of lysosomal ATP accumulation suppresses autophagic flux by regulating lysosomal function in cisplatin-resistant cells. As accumulation of lysosomal ATP is critical for normal lysosomal function (28), we next measured 
A

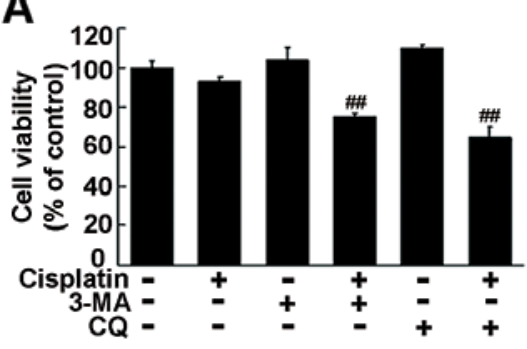

C
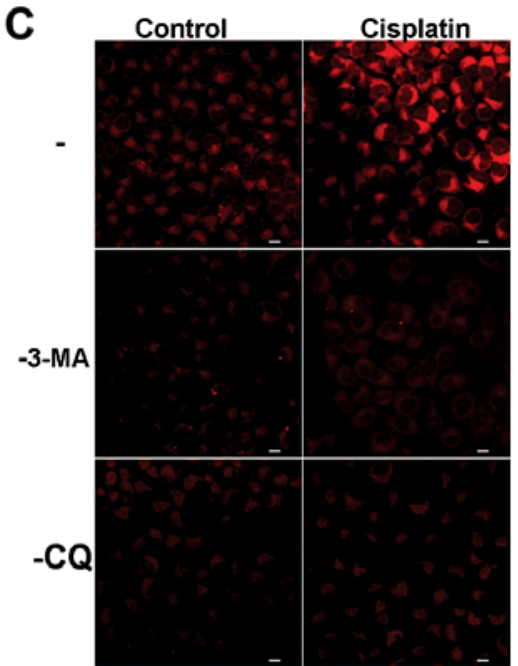

E

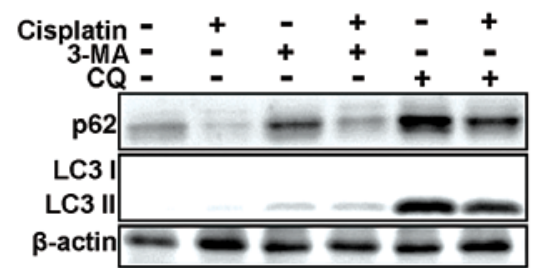

G

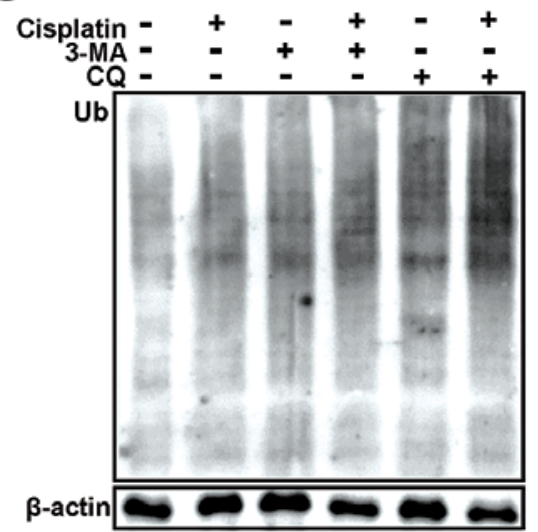

B
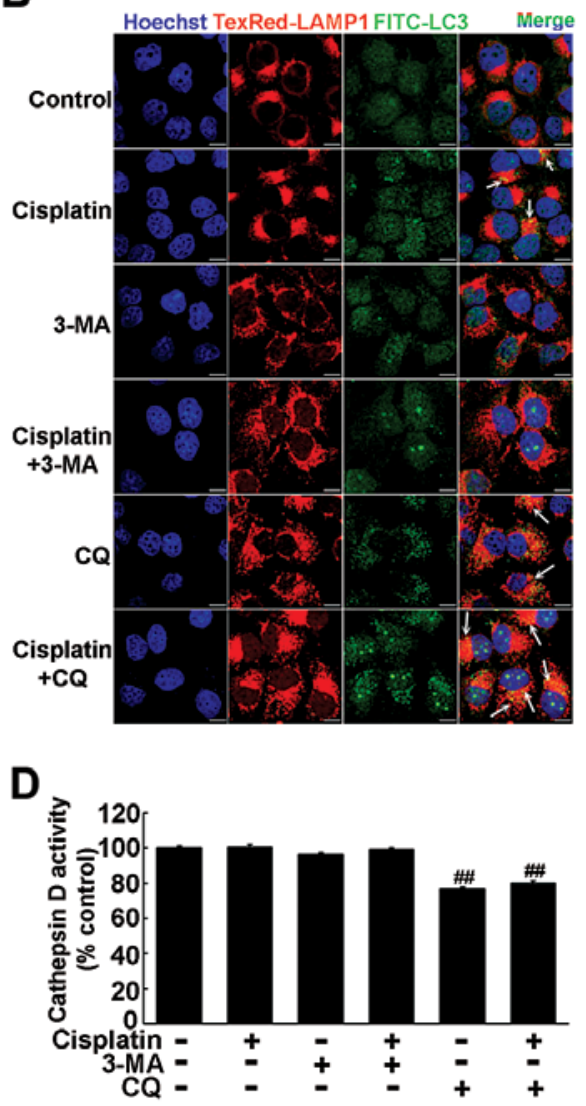

F

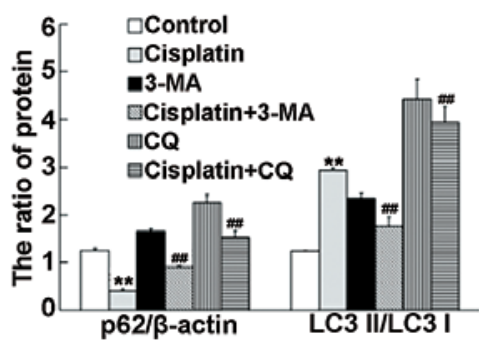

H

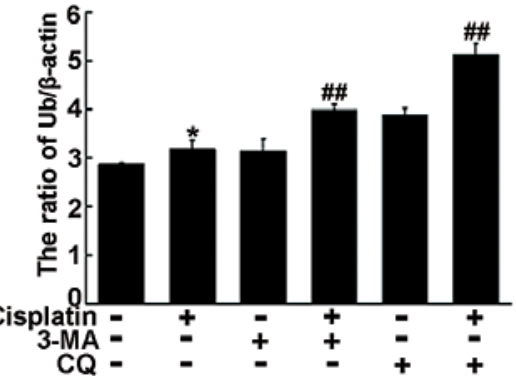

Figure 3. Inhibition of autophagy enhances cisplatin cytotoxicity in cisplatin-resistant SKOV3/DDP cells, but targeting the lysosome to disrupt autolysosome formation is more effective (A) SKOV3/DDP cells were treated with cisplatin $(6 \mu \mathrm{g} / \mathrm{ml})$ in combination with 3-MA (10 mM) or CQ (50 $\mu \mathrm{M})$ for $24 \mathrm{~h}$ Cell viability was determined by MTT assay. Data are presented as mean $\pm \mathrm{SD}, \mathrm{n}=3$. ${ }^{\# /} \mathrm{P}<0.05$ vs. cisplatin. (B) Colocalization of LAMP1 and LC3 was observed by confocal microscopy in SKOV3/DDP cells treated as indicated in panel A (scale bar, $10 \mu \mathrm{m}$; arrows indicate colocalization of LAMP1 and LC3). (C) LysoTracker staining in SKOV3/DDP cells treated with cisplatin $(6 \mu \mathrm{g} / \mathrm{ml})$ in combination with 3-MA $(10 \mathrm{mM})$ or CQ $(50 \mu \mathrm{M})$ for $12 \mathrm{~h}$ was observed by confocal microscopy (scale bar, $10 \mu \mathrm{m}$ ). (D) Following treatments indicated in panel C, cells were lysed in CD cell lysis buffer and lysates analyzed using a cathepsin $\mathrm{D}$ activity assay. Data are presented as mean $\pm \mathrm{SD}, \mathrm{n}=3 .{ }^{\# \#} \mathrm{P}<0.01$ vs. cisplatin. (E and $\mathrm{G}$ ) Western blot analysis of LC3II/LC3I, p62, and ubiquitinated protein levels in SKOV3/DDP cells treated as indicated in panel A. (F and H) Quantitation of LC3II/LC3I, p62, and ubiquitinated protein levels. Data are presented as mean $\pm \mathrm{SD}, \mathrm{n}=3 .{ }^{*} \mathrm{P}<0.05,{ }^{* *} \mathrm{P}<0.01$ vs. control; ${ }^{* \#} \mathrm{P}<0.01$ vs. cisplatin.

the ATP content of lysosomes in cisplatin-sensitive SKOV3 cells and cisplatin-resistant SKOV3/DDP cells. Compared with un-treated SKOV3 cells, lysosomes of un-treated SKOV3/DDP cells contained more ATP (Fig. 6A). Following 

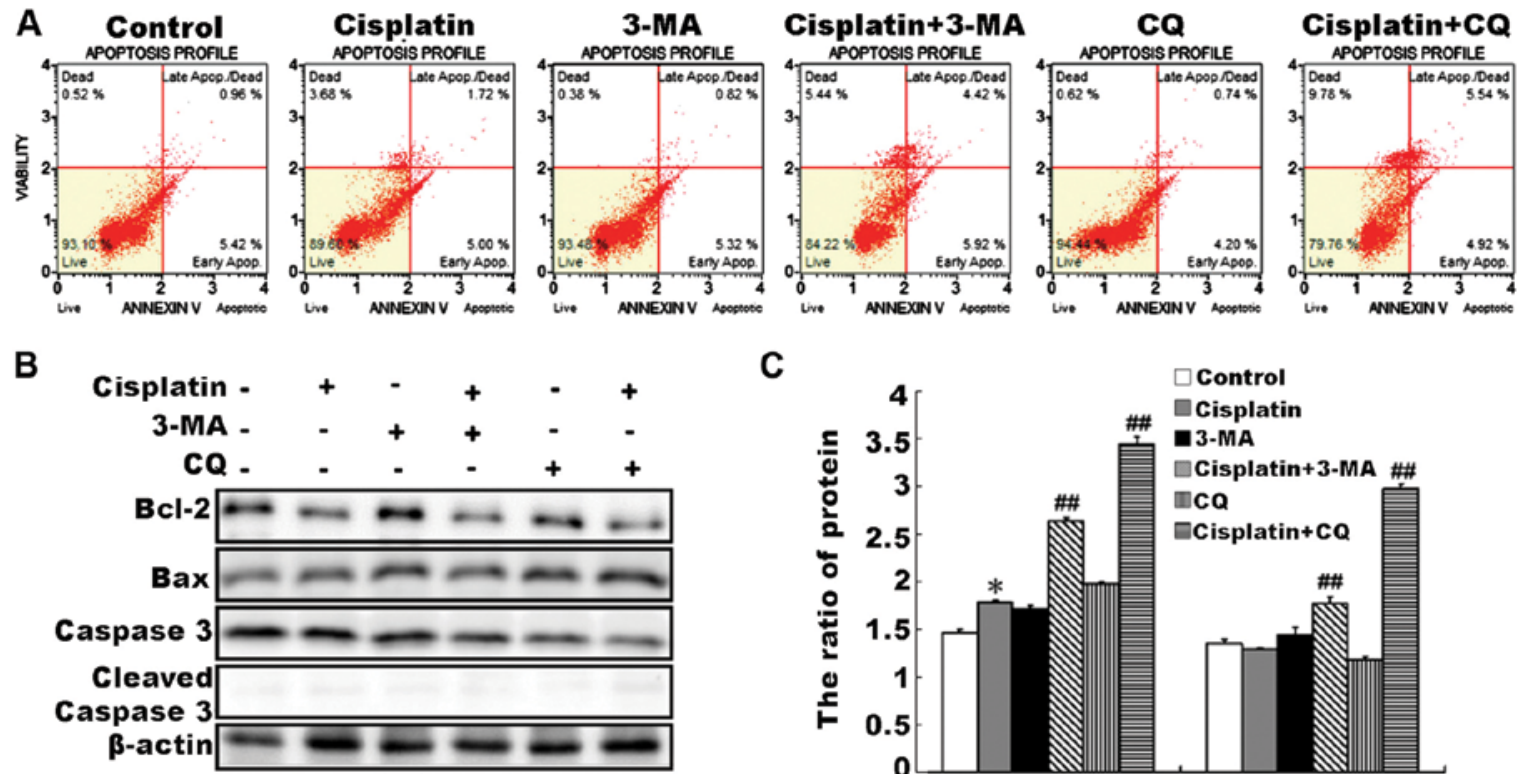

C
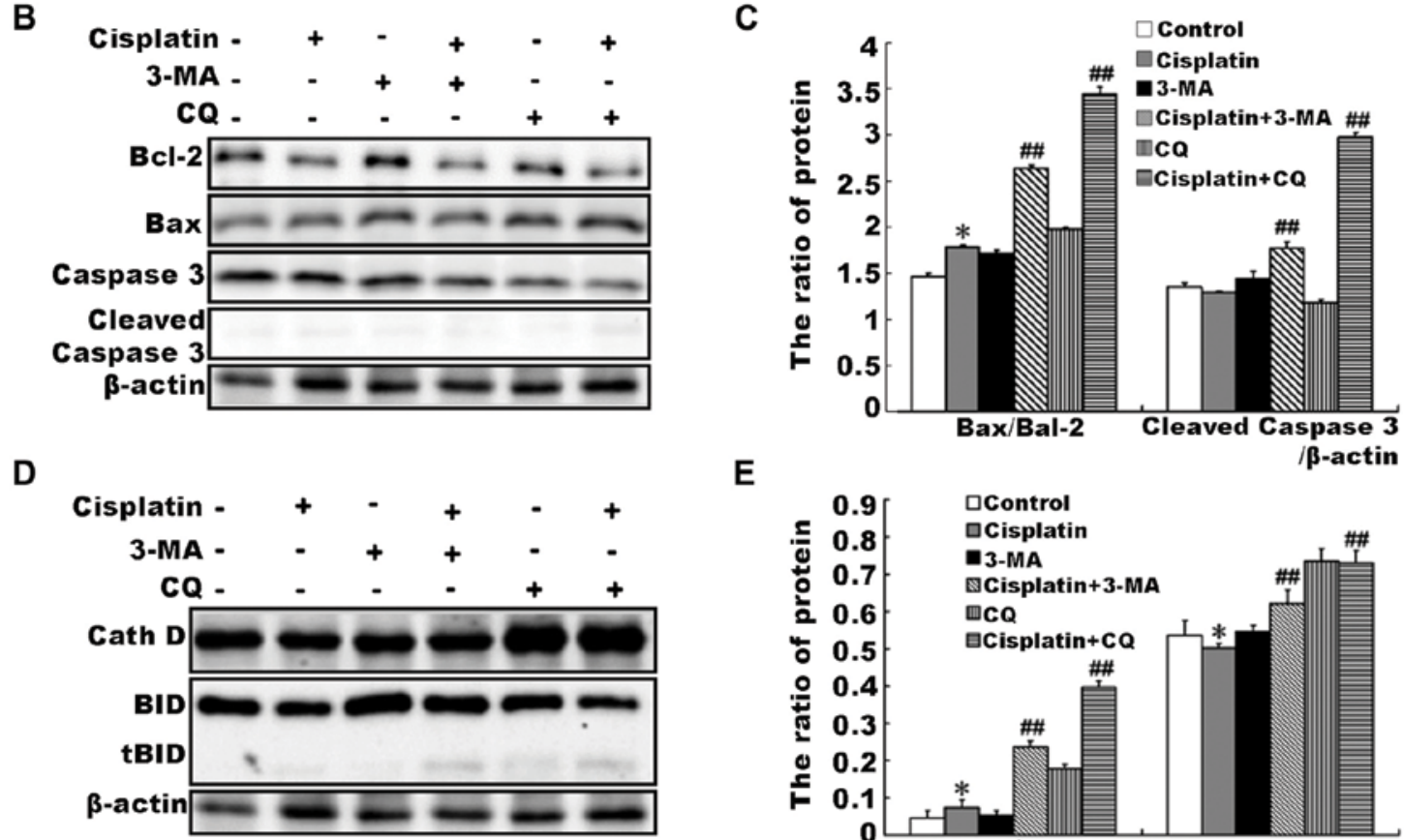

E

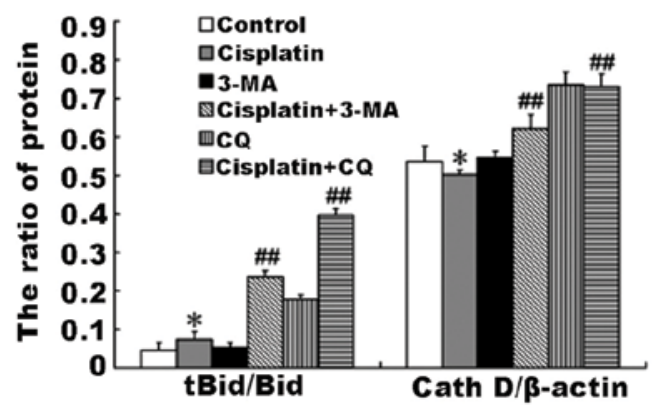

Figure 4. Inhibition of autophagy by targeting the lysosome initiates cell death by triggering mitochondria-lysosome crosstalk in cisplatin-resistant SKOV3/DDP cells. (A) SKOV3/DDP cells were co-treated with cisplatin and 3-MA or CQ for $24 \mathrm{~h}$ and then stained with Muse ${ }^{\mathrm{TM}}$ Annexin V and Dead Cell reagent. Positively stained cells were counted with the Muse ${ }^{\mathrm{TM}}$ Cell Analyzer. Data are presented as mean $\pm \mathrm{SD}, \mathrm{n}=3$. (B and D) Western blot analysis of Bax/Bcl-2, cleaved caspase-3, cathepsin D, and tBid/Bid protein levels in SKOV3/DDP cells treated as indicated in panel A. (C and E) Quantitation of Bax/Bcl-2, cleaved caspase-3, cathepsin D, and tBid/Bid levels. Data are presented as mean $\pm \mathrm{SD}, \mathrm{n}=3$. ${ }^{*} \mathrm{P}<0.05$ vs. control; ${ }^{\# \#} \mathrm{P}<0.01$ vs. cisplatin.

treatment with cisplatin for $12 \mathrm{~h}$, the level of lysosomal ATP in SKOV3 cells slightly increased. SKOV3/DDP cells always contained abundant ATP, with cisplatin augmenting this high level. The anion transport inhibitor DIDS inhibits lysosomal ATP accumulation by inhibiting activity of SLC17A9, which is enriched in lysosomes (28). Therefore, we treated SKOV3/ DDP cell combinations of DIDS and cisplatin to investigate the effect of inhibiting lysosomal ATP accumulation on cisplatin sensitivity. Treatment with DIDS significantly decreased lysosomal ATP accumulation, more so when combining DIDS with cisplatin (Fig. 6B).

We next investigated the effect of blocking lysosomal ATP accumulation on lysosomal degradation of autophagolysosomal materials in SKOV3/DDP cells. Compared with cisplatin alone, co-treatment of SKOV3/DDP cells with DIDS and cisplatin more effectively inhibited p62 degradation and increased accumulation of LC3II (Fig. 6C and D). Co-treatment with DIDS and cisplatin also yielded larger and more numerous autolysosomes (Fig. 6E). We also evaluated lysosomal function following co-treatment of SKOV3/DDP cells with DIDS and cisplatin by LysoTracker staining and measuring cathepsin D activity. Co-treatment with DIDS and cisplatin abolished LysoTracker staining, and reduced cathepsin D enzyme activity (Fig. 6F and G). These results suggest that lysosomes of cisplatin-resistant SKOV3/DDP cells have more ATP than cisplatin-sensitive SKOV3 cells. Moreover, inhibition of lysosomal ATP can impair lysosomal function to block autophagic flux.

\section{Discussion}

Platinum-based chemotherapy remains the primary treatment strategy for ovarian cancer, with cisplatin commonly employed (34). Non-small cell lung cancer, cervical cancer, and ovarian cancer cells treated with cisplatin commonly activate the autophagic process to mitigate cisplatin-induced apoptosis $(10,35)$. We identified an increased ratio of LC3II/LC3I following treatment of SKOV3 or SKOV3/DDP cells with cisplatin. This phenomenon was more pronounced in cisplatin-resistant SKOV3/DDP cells, in which levels of p62 were also decreased. These results suggest that cisplatin induces activation of autophagy in both SKOV3 and SKOV3/DDP cells, but a higher level of activation is induced in SKOV3/DDP cells.

During tumor formation, autophagy activation inhibits tumor growth. However, in solid tumors, autophagy promotes 

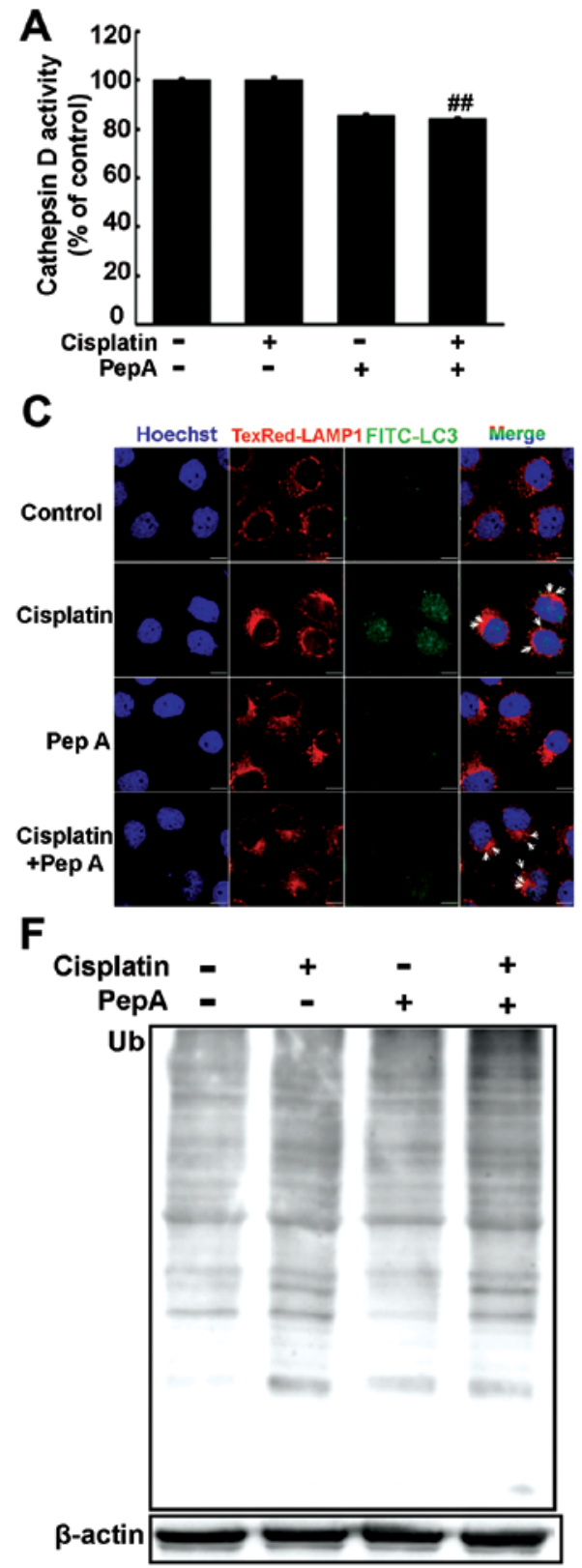

B

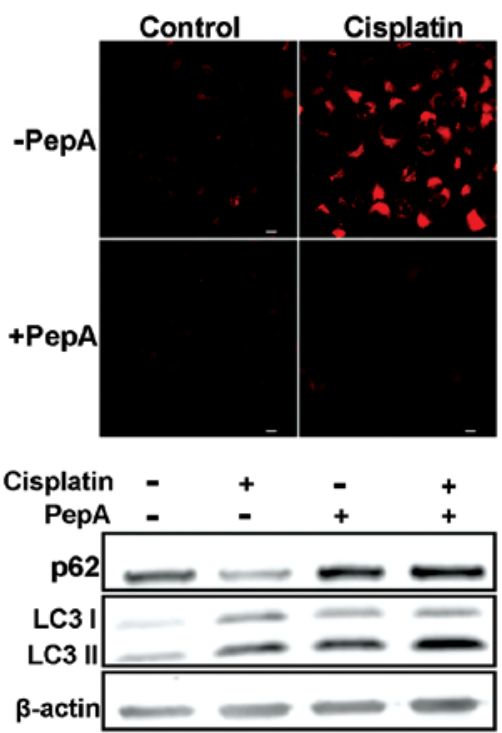

E

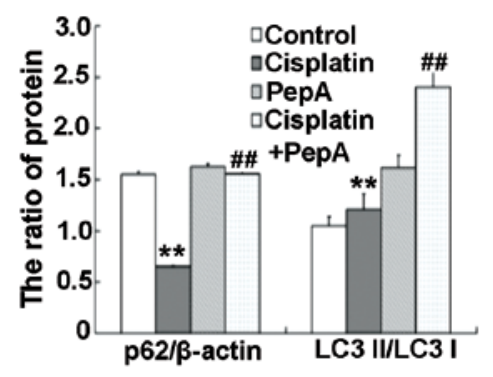

G

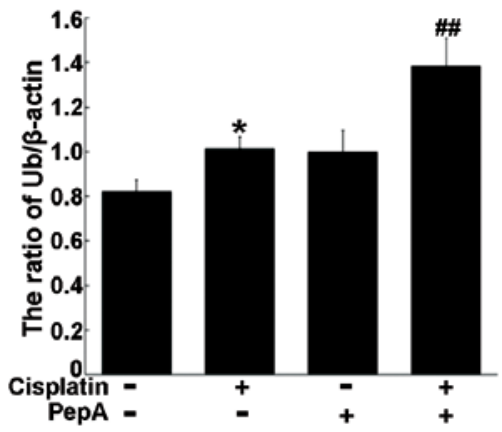

Figure 5. Inhibition of cathepsin D impairs autophagic degradation in cisplatin-resistant SKOV3/DDP cells. (A) Cells were treated with Pepstatin A (80 $\mu \mathrm{M})$ and/or cisplatin $(6 \mu \mathrm{g} / \mathrm{ml})$ for $12 \mathrm{~h}$ and lysed in CD cell lysis buffer. Lysates were analyzed using a cathepsin D activity assay. Data are presented as mean $\pm \mathrm{SD}$, $\mathrm{n}=3$. ${ }^{\# \#} \mathrm{P}<0.01$ vs. cisplatin. (B) LysoTracker staining in SKOV3/DDP cells treated as indicated in panel A and observed by confocal microscopy (scale bar, $10 \mu \mathrm{m}$ ). (C) Colocalization of LAMP1 and LC3 in SKOV3/DDP cells treated as indicated in panel A was observed by confocal microscopy (scale bar, $10 \mu \mathrm{m}$; arrows indicate colocalization of LAMP1 and LC3). (D and F) Western blot analysis of p62, LC3II/LC3I, and ubiquitinated protein levels in SKOV3/DDP cells treated as indicated in panel A. (E and G) Quantitation of p62, LC3II/LC3I, and ubiquitinated protein levels. Data are presented as mean $\pm \mathrm{SD}, \mathrm{n}=3 .{ }^{*} \mathrm{P}<0.05,{ }^{* *} \mathrm{P}<0.01$ vs. control; ${ }^{\# \#} \mathrm{P}<0.01$ vs. cisplatin.

tumor cell survival by mitigating the consequences of stress. In the course of autophagy, the predominant role of lysosomes is clearing autolysosomal material, and lysosomal proteases are required for degradation of accumulated proteins within lysosomes (36). We identified increased expression of LAMP1 and cathepsin D in cisplatin-resistant SKOV3/DDP cells following treatment with or without cisplatin. These findings suggest that SKOV3/DDP cells possess more lysosomes than SKOV3 cells. Moreover, lysosomal function is activated in SKOV3/DDP cells during cisplatin-induced autophagy. Therefore, lysosomes may be involved in mediating cisplatin resistance in SKOV3/DDP cells. Yu et al have reported that many lysosomes are consumed during autophagy, but autophagic lysosome reformation (ALR) allows the cell to restore lysosomal homeostasis (33). We speculate that abundant formation of autolysosomes may provide the basic conditions for ALR to restore lysosomal homeostasis, though the precise mechanisms require further elucidation.

Inhibiting autophagy can effectively enhance the cytotoxicity of anticancer chemotherapeutics (35). For example, malignant glioma cells are more responsive to imatinib following inhibition of late-stage autophagy (37). We observed enhanced cisplatin-induced cytotoxicity in SKOV3/DDP cells 
A

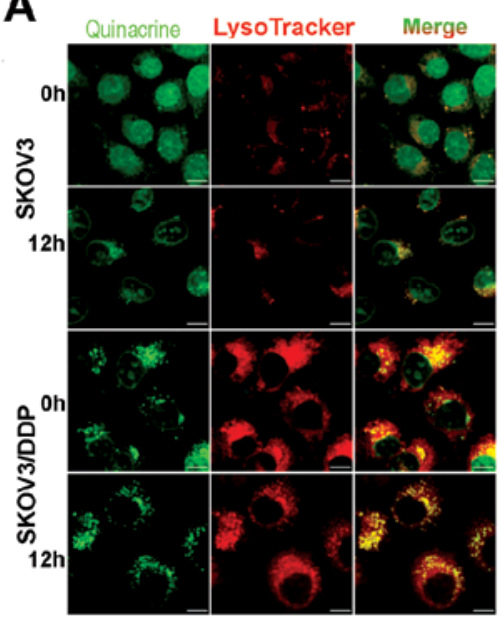

C

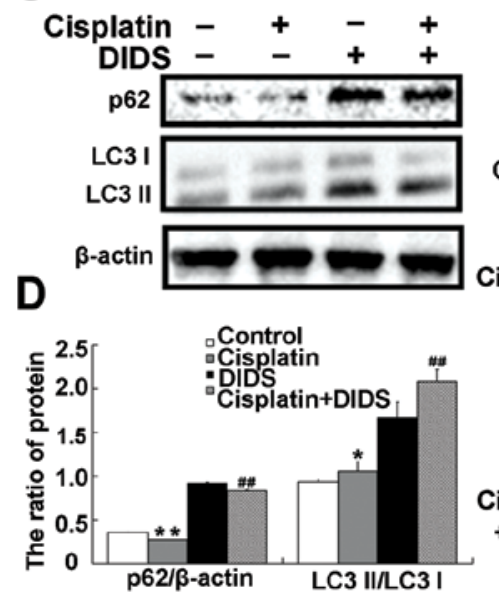

$\mathbf{F}$

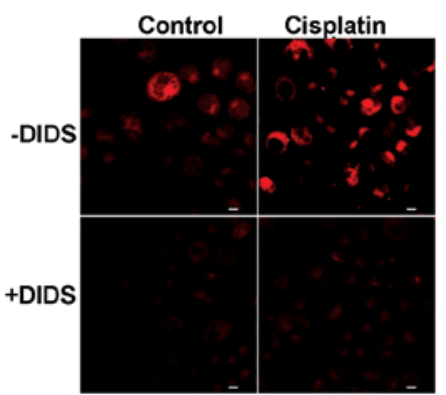

B

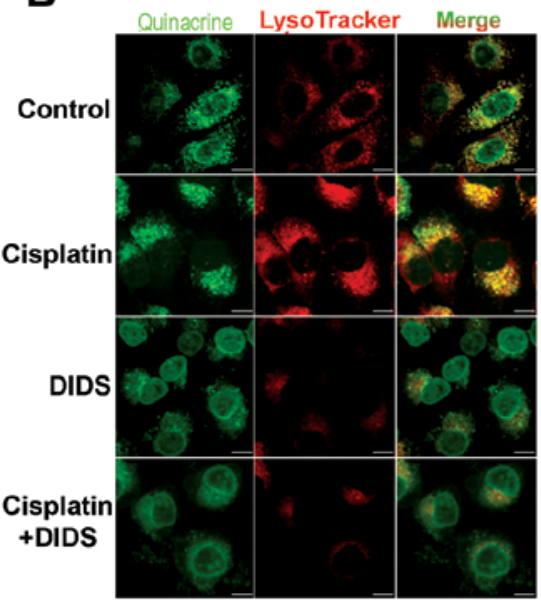

E

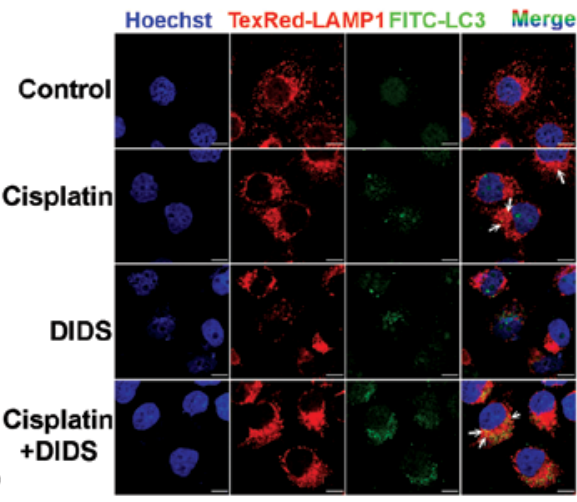

G

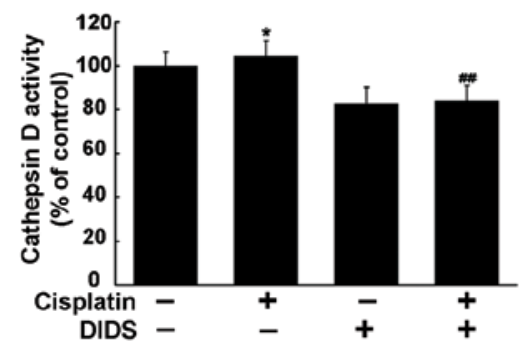

Figure 6. Inhibition of ATP transport into lysosomes suppresses autophagic flux in cisplatin-resistant cells. (A) SKOV3 and SKOV3/DDP cells were treated with cisplatin $(6 \mu \mathrm{g} / \mathrm{ml})$ for 0 and $12 \mathrm{~h}$ and stained with quinacrine and LysoTracker Red DND-99. Green (quinacrine) and red (LysoTracker) signals were observed by confocal microscopy (scale bar, $10 \mu \mathrm{m}$ ). (B) SKOV3/DDP cells were treated with $40 \mu \mathrm{M}$ DIDS and $6 \mu \mathrm{g} / \mathrm{ml}$ cisplatin for $20 \mathrm{~h}$, and stained with quinacrine and LysoTracker Red DND-99. Green (quinacrine) and red (LysoTracker) signals were observed by confocal microscopy (scale bar, $10 \mu \mathrm{m}$ ). (C) Western blot analysis of p62 and LC3II/LC3I protein levels in SKOV3/DDP cells treated as indicated in panel B. (D) Quantitation of p62 and LC3II/LC3I protein levels. Data are presented as mean $\pm \mathrm{SD}, \mathrm{n}=3$. ${ }^{\mathrm{P}} \mathrm{P}<0.05,{ }^{* *} \mathrm{P}<0.01$ vs. control; ${ }^{*} \mathrm{P}<0.01$ vs. cisplatin. (E) Colocalization of LAMP1 and LC3 was observed by confocal microscopy in SKOV3/DDP cells treated as indicated in panel B (scale bar, $10 \mu \mathrm{m}$; arrows indicate the colocalization of LAMP1 and LC3). (F) SKOV3/DDP cells were treated as indicated in panel B and LysoTracker (LTR) staining was observed by confocal microscopy (scale bar, $10 \mu \mathrm{m}$ ). (G) Following treatment as indicated in panel B, cells were lysed in CD cell lysis buffer and lysates analyzed using a cathepsin D activity assay. Data are presented as mean \pm SD, $n=3$. ${ }^{*} \mathrm{P}<0.05$ vs. control; ${ }^{\#} \mathrm{P}<0.01$ vs. cisplatin.

following treatment with either 3-MA or CQ. Additionally, combination treatment with cisplatin and CQ could more effectively disturbs lysosomal function to lead to autolysosome accumulation. Further, autophagic flux was blocked following cisplatin-CQ combination treatment of SKOV3/DDP cells. Therefore, activation of autophagy protects SKOV3/DDP cells from cisplatin-induced apoptosis, and targeting the lysosome to inhibit autophagy could more efficiently increase cisplatin-sensitivity of SKOV3/DDP cells.

While lysosomes protect cancer cells from chemotherapy-induced apoptosis, lysosome permeabilization leads to a gradual leakage of cathepsins and other hydrolases 
from the lysosomal lumen into the cytosol. These enzymes then initiate a cell death pathway (38). During induction of lysosomal-associated cell death, lysosomal cathepsins B and D translocate to the cytosol where they activate Bid and induce mitochondrial outer membrane permeabilization (38-40). We found that combination treatment of SKOV3/DDP cells with cisplatin and CQ could upregulate active tBID, increase the ratio of $\mathrm{Bax} / \mathrm{Bcl}-2$, and stimulate cleavage of caspase-3. Thus, targeting the lysosome could enhance cisplatin cytotoxicity in cisplatin-resistant SKOV3/DDP cells by triggering mitochondria-lysosome crosstalk. Our results further support a role for lysosomes in chemotherapeutic resistance in certain cancers.

Cathepsin D is normally localized within the lysosome, where it degrades materials delivered to lysosomes $(39,41)$. Abnormal expression and/or function of many lysosomal hydrolases can be found in various cancers, and these abnormalities are frequently associated with tumor recurrence and disease prognosis (42-44). Cathepsin D is also associated with the activation of autophagy in human malignant glioblastoma cells and cervical cancer cells (45). Additionally, inhibition of cathepsin D activity can impair degradation of autolysosome contents (46). Reduced levels or activity of cathepsin B and D impairs lysosomal function, leading to accumulation of undegraded material in autolysosomes and delayed ALR (47). We identified a relatively high level of cathepsin D in SKOV3/DDP cells compared with that in SKOV3 cells. Moreover, inhibition of cathepsin D activity in SKOV3/DDP cells impaired lysosomal function to block cisplatin-induced autophagic degradation. This led to an enlargement of autolysosomes, and possibly disturbed ALR. These findings reflect the importance of the lysosome and lysosomal proteases such as cathepsin D in maintaining cell homeostasis by removing accumulated proteins. Autophagy may play a critical role in cisplatin resistance in ovarian cancer cells. However, the precise mechanisms by which lysosomal function is regulated during autophagy requires further study.

The lysosomes of astrocytes and other cell lines contain a high level of ATP, which plays a crucial role in maintaining lysosomal physiology and enables activation of proteases such as cathepsin D $(28,29,48,49)$. ATP-sensitive sodium and potassium channels are required for maintaining the low $\mathrm{pH}$ of the lysosomal lumen, and need ATP to supply energy for their function (27). The lysosomes of untreated SKOV3/DDP cells contained more ATP than the SKOV3 cells. Moreover, lysosomes in both SKOV3 and SKOV3/DDP cells possessed slightly higher levels of ATP following cisplatin treatment. This lysosomal ATP may be needed to maintain lysosomal function and permit activation of lysosomal proteases. Combination treatment with cisplatin and the inhibitor of lysosomal ATP accumulation, DIDS, weakened LysoTracker staining, inhibited cathepsin D activity, and increased accumulation of autolysosomes and expression of p62. This suggests a combination of inhibiting lysosomal ATP and cisplatin could impair lysosomal function and autophagic degradation. Previous studies showed changes to levels of lysosomal nutrients and energy can activate mTORC1, facilitating the cycle of lysosomal consumption and restoration by regulating ALR $(28,33)$. Therefore, we speculate that abundant lysosomal ATP induces activation of mTORC1 and promotes ALR, thereby enabling lysosomal function and the maintenance of lysosome homeostasis. These processes then contribute to cisplatin resistance in cancer.

In summary, following cisplatin treatment, autophagy was activated in SKOV3/DDP cells to enable cell survival. Targeting the lysosome inhibited autophagy to effectively enhance cisplatin-induced cytotoxicity and initiated lysosomal cell death by triggering mitochondria-lysosome crosstalk in SKOV3/DDP cells. The presence of sufficient cathepsin D enables maintenance of lysosomal function and lysosome homeostasis in cisplatin-resistant SKOV3/DDP cells. These effects may be dependent on lysosomal ATP levels, because ATP-mediated lysosomal function is required for cisplatin-induced autophagy. Our findings suggest that lysosomes are involved in mediating cisplatin resistance in ovarian carcinoma cells. Therefore, these observations indicate that lysosomes represent a therapeutic target for re-sensitizing cisplatin-resistant cancer cells to chemotherapy.

\section{Acknowledgements}

The present study was supported by the National Natural Science Foundation of China (grant nos. 81202552, 20140520018JH, 81372793 and 81272876), and the Postdoctoral Science Foundation of China (no. 2013M540256).

\section{References}

1. Jemal A, Siegel R, Ward E, Hao Y, Xu J and Thun MJ: Cancer statistics, 2009. CA Cancer J Clin 59: 225-249, 2009.

2. Shen W, Liang B, Yin J, Li X and Cheng J: noscapine increases the sensitivity of drug-resistant ovarian cancer cell line SKOV3/DDP to cisplatin by regulating cell cycle and activating apoptotic pathways. Cell Biochem Biophys: Dec 16, 2014 (Epub ahead of print).

3. Yakirevich E, Sabo E, Naroditsky I, Sova Y, Lavie O and Resnick MB: Multidrug resistance-related phenotype and apoptosis-related protein expression in ovarian serous carcinomas. Gynecol Oncol 100: 152-159, 2006.

4. Basu A and Krishnamurthy S: Cellular responses to cisplatin-induced DNA damage. J Nucleic Acids 2010: 201367, 2010.

5. Wang $\mathbf{J}$ and $\mathrm{Wu}$ GS: Role of autophagy in cisplatin resistance in ovarian cancer cells. J Biol Chem 289: 17163-17173, 2014.

6. Sun Y, Liu JH, Jin L, Sui YX, Lai L and Yang Y: Inhibition of Beclin 1 expression enhances cisplatin-induced apoptosis through a mitochondrial-dependent pathway in human ovarian cancer SKOV3/DDP cells. Oncol Res 21: 261-269, 2014.

7. Zhang HQ, He B, Fang N, Lu S, Liao YQ and Wan YY: Autophagy inhibition sensitizes cisplatin cytotoxicity in human gastric cancer cell line SGC7901. Asian Pac J Cancer Prev 14: 4685-4688, 2013.

8. Xu N, Zhang J, Shen C, Luo Y, Xia L, Xue F and Xia Q: Cisplatin-induced downregulation of miR-199a-5p increases drug resistance by activating autophagy in $\mathrm{HCC}$ cell. Biochem Biophys Res Commun 423: 826-831, 2012.

9. Kang R, Wang ZH, Wang BQ, Zhang CM, Gao W, Feng Y, Bai T, Zhang HL, Huang-Pu H and Wen SX: Inhibition of autophagy-potentiated chemosensitivity to cisplatin in laryngeal cancer Hep-2 cells. Am J Otolaryngol 33: 678-684, 2012.

10. Klionsky DJ: Autophagy: From phenomenology to molecular understanding in less than a decade. Nat Rev Mol Cell Biol 8: 931-937, 2007.

11. Wu WK, Coffelt SB, Cho CH, Wang XJ, Lee CW, Chan FK, Yu J and Sung JJ: The autophagic paradox in cancer therapy. Oncogene 31: 939-953, 2012.

12. Xu Y, Yu H, Qin H, Kang J, Yu C, Zhong J, Su J, Li H and Sun L: Inhibition of autophagy enhances cisplatin cytotoxicity through endoplasmic reticulum stress in human cervical cancer cells. Cancer Lett 314: 232-243, 2012.

13. Yu C, Huang X, Xu Y, Li H, Su J, Zhong J, Kang J, Liu Y and Sun L: Lysosome dysfunction enhances oxidative stress-induced apoptosis through ubiquitinated protein accumulation in Hela cells. Anat Rec (Hoboken) 296: 31-39, 2013. 
14. Yu H, Su J, Xu Y, Kang J, Li H, Zhang L, Yi H, Xiang X, Liu F and Sun L: p62/SQSTM1 involved in cisplatin resistance in human ovarian cancer cells by clearing ubiquitinated proteins. Eur J Cancer 47: 1585-1594, 2011

15. Korolchuk VI and Rubinsztein DC: Regulation of autophagy by lysosomal positioning. Autophagy 7: 927-928, 2011.

16. Kroemer G and Jäättelä M: Lysosomes and autophagy in cell death control. Nat Rev Cancer 5: 886-897, 2005

17. de Duve C: The lysosome turns fifty. Nat Cell Biol 7: 847-849, 2005.

18. Rajapakshe AR, Podyma-Inoue KA, Terasawa K, Hasegawa K, Namba T, Kumei Y, Yanagishita $M$ and Hara-Yokoyama M: Lysosome-associated membrane proteins (LAMPs) regulate intracellular positioning of mitochondria in MC3T3-E1 cells. Exp Cell Res 331: 211-222, 2015.

19. Carlsson SR, Roth J, Piller F and Fukuda M: Isolation and characterization of human lysosomal membrane glycoproteins, h-lamp-1 and h-lamp-2. Major sialoglycoproteins carrying polylactosaminoglycan. J Biol Chem 263: 18911-18919, 1988.

20. Chen JW, Pan W, D'Souza MP and August JT: Lysosome-associated membrane proteins: Characterization of LAMP-1 of macrophage P388 and mouse embryo 3T3 cultured cells. Arch Biochem Biophys 239: 574-586, 1985.

21. Eskelinen EL, Schmidt CK, Neu S, Willenborg M, Fuertes G, Salvador N, Tanaka Y, Lüllmann-Rauch R, Hartmann D, Heeren $\mathrm{J}$, et al: Disturbed cholesterol traffic but normal proteolytic function in LAMP-1/LAMP-2 double-deficient fibroblasts. Mol Biol Cell 15: 3132-3145, 2004.

22. Kanai K: Biology of the mycobacterioses. Some aspects of the lysosome-bacillus interaction in experimental mouse tuberculosis. Ann N Y Acad Sci 154 (1 Biology of My): 177-193, 1968.

23. Zhou J, Tan SH, Nicolas V, Bauvy C, Yang ND, Zhang J, Xue Y, Codogno P and Shen HM: Activation of lysosomal function in the course of autophagy via mTORC1 suppression and autophagosome-lysosome fusion. Cell Res 23: 508-523, 2013.

24. Zhitomirsky B and Assaraf YG: Lysosomal sequestration of hydrophobic weak base chemotherapeutics triggers lysosomal biogenesis and lysosome-dependent cancer multidrug resistance. Oncotarget 6: 1143-1156, 2015

25. Wang E, Lee MD and Dunn KW: Lysosomal accumulation of drugs in drug-sensitive MES-SA but not multidrug-resistant MES-SA/Dx5 uterine sarcoma cells. J Cell Physiol 184: 263-274, 2000.

26. Braun M, Waheed A and von Figura K: Lysosomal acid phosphatase is transported to lysosomes via the cell surface. EMBO J 8: 3633-3640, 1989.

27. Ishida Y, Nayak S, Mindell JA and Grabe M: A model of lysosomal pH regulation. J Gen Physiol 141: 705-720, 2013.

28. Cao Q, Zhao K, Zhong XZ, Zou Y, Yu H, Huang P, Xu TL and Dong XP: SLC17A9 protein functions as a lysosomal ATP transporter and regulates cell viability. J Biol Chem 289: 23189-23199, 2014.

29. Pillai S and Zull JE: Effects of ATP, vanadate, and molybdate on cathepsin D-catalyzed proteolysis. J Biol Chem 260: 8384-8389, 1985.

30. Aits $S$ and Jäättelä M: Lysosomal cell death at a glance. J Cell Sci 126: 1905-1912, 2013.

31. Foghsgaard L, Wissing D, Mauch D, Lademann U, Bastholm L, Boes M, Elling F, Leist M and Jäättelä M: Cathepsin B acts as a dominant execution protease in tumor cell apoptosis induced by tumor necrosis factor. J Cell Biol 153: 999-1010, 2001.

32. Sathe MN, Woo K, Kresge C, Bugde A, Luby-Phelps K, Lewis MA and Feranchak AP: Regulation of purinergic signaling in biliary epithelial cells by exocytosis of SLC17A9-dependent ATP-enriched vesicles. J Biol Chem 286: 25363-25376, 2011.
33. Yu L, McPhee CK, Zheng L, Mardones GA, Rong Y, Peng J, Mi N, Zhao Y, Liu Z, Wan F, et al: Termination of autophagy and reformation of lysosomes regulated by mTOR. Nature 465 : 942-946, 2010

34. Kelland L: The resurgence of platinum-based cancer chemotherapy. Nat Rev Cancer 7: 573-584, 2007.

35. Amaravadi RK, Yu D, Lum JJ, Bui T, Christophorou MA, Evan GI, Thomas-Tikhonenko A and Thompson CB: Autophagy inhibition enhances therapy-induced apoptosis in a Myc-induced model of lymphoma. J Clin Invest 117: 326-336, 2007.

36. Sagulenko V, Muth D, Sagulenko E, Paffhausen T, Schwab M and Westermann F: Cathepsin D protects human neuroblastoma cells from doxorubicin-induced cell death. Carcinogenesis 29: 1869-1877, 2008

37. Shingu T, Fujiwara K, Bögler O, Akiyama Y, Moritake K, Shinojima N, Tamada Y, Yokoyama T and Kondo S: Inhibition of autophagy at a late stage enhances imatinib-induced cytotoxicity in human malignant glioma cells. Int J Cancer 124: 1060-1071, 2009.

38. Boya P and Kroemer G: Lysosomal membrane permeabilization in cell death. Oncogene 27: 6434-6451, 2008.

39. Benes P, Vetvicka V and Fusek M: Cathepsin D - many functions of one aspartic protease. Crit Rev Oncol Hematol 68: 12-28, 2008.

40. Yin L, Stearns R and González-Flecha B: Lysosomal and mitochondrial pathways in $\mathrm{H}_{2} \mathrm{O}_{2}$-induced apoptosis of alveolar type II cells. J Cell Biochem 94: 433-445, 2005.

41. Diment S, Martin KJ and Stahl PD: Cleavage of parathyroid hormone in macrophage endosomes illustrates a novel pathway for intracellular processing of proteins. J Biol Chem 264: 13403-13406, 1989.

42. Vasiljeva O, Reinheckel T, Peters C, Turk D, Turk V and Turk B: Emerging roles of cysteine cathepsins in disease and their potential as drug targets. Curr Pharm Des 13: 387-403, 2007.

43. Kuester D, Lippert H, Roessner A and Krueger S: The cathepsin family and their role in colorectal cancer. Pathol Res Pract 204: 491-500, 2008.

44. Miao HQ, Liu H, Navarro E, Kussie P and Zhu Z: Development of heparanase inhibitors for anti-cancer therapy. Curr Med Chem 13: 2101-2111, 2006.

45. Hah YS, Noh HS, Ha JH, Ahn JS, Hahm JR, Cho HY and Kim DR: Cathepsin D inhibits oxidative stress-induced cell death via activation of autophagy in cancer cells. Cancer Lett 323: 208-214, 2012

46. Tatti M, Motta M, Di Bartolomeo S, Cianfanelli V and Salvioli R Cathepsin-mediated regulation of autophagy in saposin C deficiency. Autophagy 9: 241-243, 2013.

47. Tatti M, Motta M, Di Bartolomeo S, Scarpa S, Cianfanelli V, Cecconi F and Salvioli R: Reduced cathepsins B and D cause impaired autophagic degradation that can be almost completely restored by overexpression of these two proteases in Sap C-deficient fibroblasts. Hum Mol Genet 21: 5159-5173, 2012.

48. Zhang Z, Chen G, Zhou W, Song A, Xu T, Luo Q, Wang W, Gu XS and Duan S: Regulated ATP release from astrocytes through lysosome exocytosis. Nat Cell Biol 9: 945-953, 2007.

49. Huang P, Zou Y, Zhong XZ, Cao Q, Zhao K, Zhu MX, Murrell-Lagnado R and Dong XP: P2X4 forms functional ATP-activated cation channels on lysosomal membranes regulated by luminal pH. J Biol Chem 289: 17658-17667, 2014. 